\title{
DIFFUSION IN NATURAL POROUS MEDIA: \\ Contaminant Transport, Sorption/Desorption and Dissolution Kinetics
}


THE KLUWER INTERNATIONAL SERIES

\title{
TOPICS IN \\ ENVIRONMENTAL FLUID MECHANICS
}

\author{
Series Editors
}

Dr. Philip Chatwin, University of Sheffield, UK

Dr.Gedeon Dagan, Tel Aviv University, ISRAEL

Dr. John List, California Institute of Technology, USA

Dr. Chiang Mei, Massachusetts Institute of Technology, USA

Dr. Stuart Savage, McGill University, CANADA

Topics for the new series include, but are not limited to:

- Small-to medium scale atmospheric dynamics: turbuience, convection, dispersion, aerosols, buoyant plumes, air pollution over cities

- Coastal oceanography: air-sea interaction, wave climate, wave interaction with tides, current structures and coastlines, sediment transport and shoreline evolution

- Estuary dynamics: sediment transport, cohesive sediments, density stratification, salinity intrusion, thermal pollution, dispersion, fluid-mud dynamics, and the effects of flow on the transport of toxic wastes

- Physical limnology: internal seiches, sediment resuspensions, nutrient distribution, and wind-induced currents

- Subsurface flow and transport (the unsaturated zone and groundwater): diffusion and dispersion of solutes, fingering, macropore flow, reactive solutes, motion of organics and non-aqueous liquids, volatilization, microbial effects on organics, density effects, colloids motion and effect, and effects of field scale heterogeneity

- Debris flows, initiated by lava flow from volcanic eruptions; mud flows caused by mountain storms; snow avalanches, granular flows, and evolution of deserts

- Oil spills on the sea surface and clean-up

- Indoor contamination: transport of particles in enclosed space, clean room technology, effects of temperature variation

- Risk assessment: industrial accidents resulting in the release of toxic or flammable gasses, assessment of air and water quality

- New methods of data acquisition: the use of HF radar, satellites, and Earth Observation Science

- Stochastic models and Mass transfer 


\title{
DIFFUSION IN NATURAL POROUS MEDIA: Contaminant Transport, Sorption/Desorption and Dissolution Kinetics
}

\author{
by \\ Peter Grathwohl \\ University of Tübingen \\ Germany
}

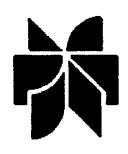

SPRINGER SCIENCE+BUSINESS MEDIA, LLC 
Grathwohl, Peter, 1958-

Diffusion in natural porous media : contaminant transport, sorption/desorption and dissolution kinetics / by Peter Grathwohl.

p. $\quad \mathrm{cm}$. -- (Environmental fluid mechanics ; 1 )

Includes bibliographical references ( $\mathrm{p} . \quad$ ) and index. ISBN 978-1-4613-7602-6 ISBN 978-1-4615-5683-1 (eBook) DOI 10.1007/978-1-4615-5683-1

1. Soil pollution. 2. Groundwater--Pollution. 3. Soil permeability. I. Title. II. Series

TD878.G73 1997

628.5'2--dc21

Copyright ${ }^{(0)} 1998$ by Springer Science+Business Media New York Originally published by Kluwer Academic Publishers in 1998

Softcover reprint of the hardcover 1st edition 1998

All rights reserved. No part of this publication may be reproduced, stored in a retrieval system or transmitted in any form or by any means, mechanical, photo-copying, recording, or otherwise, without the prior written permission of the publisher, Springer Science+Business Media, LLC.

Printed on acid-free paper. 
For Marianne and Max 


\section{CONTENTS}

FOREWORD

ACKNOWLEDGEMENTS Xiii

NOTATION Xiv

1. INTRODUCTION

1.1 Persistence of Organic Contaminants in the Subsurface Environment 1

1.2 Nonequilibrium Transport - Remediation of Contaminated Sites 5

$\begin{array}{ll}\text { 1.3 Diffusion in Sediments and Rocks } & 12\end{array}$

2. BASICS OF SORPTION AND DIFFUSION IN SOILS AND SEDIMENTS 15

2.1 Sorption of Organic Compounds in Soils and Sediments 15

$\begin{array}{lll}\text { 2.1.1 Sorption Phenomena } & 16\end{array}$

2.1.2 Partitioning of Hydrophobic Organic Compounds

$\begin{array}{ll}2.1 .3 \text { Sorption Isotherms } & 19\end{array}$

2.2 Mass Transfer by Diffusion $\quad 21$

2.2.1 Brownian Motion 21

2.2.2 Calculation of Diffusion Coefficients in Air and Water 23

2.2.3 Steady State Diffusion in Porous Media:

$\begin{array}{ll}\text { Restricted Diffusion } & 29\end{array}$

$\begin{array}{ll}\text { Tortuosity } & 31\end{array}$

2.2.4 Transient Diffusion: The Apparent Diffusion Coefficient 35

$\begin{array}{lll}2.2 .5 & \text { Surface Diffusion } & 37\end{array}$

2.2.6 Diffusion in Natural Organic Matter - Organic Polymers 38

2.2.7 Vapor Phase Diffusion in the Vadose Zone 40 
3.1 Intraparticle Diffusion $\quad 44$

3.1.1 Sorptive Uptake and Desorption (Infinite Bath) 44

3.1.2 Sorptive Uptake in Batch Systems (Bath of Limited Volume) 48

3.1.3 Comparison of Spherical to Non-Spherical Geometries 51

3.1.4 Approximation of Diffusion by First Order Kinetics 56

3.1.5 Numerical Modeling of Spherical Diffusion 59

3.1.6 Nonuniform Concentration Distributions 63

3.1.7 Sorption/Desorption Dynamics in Heterogeneous Materials 67

$\begin{array}{ll}3.2 \text { Diffusion into Layers of Low Permeability } & 73\end{array}$

3.2.1 Diffusion into and out of Semi-Infinite Porous Media 73

$\begin{array}{ll}\text { 3.2.2 Diffusion Across Layers of Low Conductivity } & 76\end{array}$

$\begin{array}{ll}\text { 3.2.3 Numerical Modeling of Diffusion in Layers } & 79\end{array}$

4. MEASURED DIFFUSION COEFFICIENTS 83

4.1 Time-Lag Experiments $\quad 84$

4.1.1 Experimental Procedure: TCE and Tracer Diffusion 84

4.1.2 Data Analysis 88

4.1.3 Example I: Diffusion Coefficients of TCE in Natural Clays 90

4.1.4 Example II: Diffusion Coefficients of TCE in Mineral Liners
Modified with Organic Additives

4.1.5 Example III: Diffusion Coefficients of TCE and lodide
(Tracer) in Sedimentary Rocks

4.1.6 Example IV: Low Diffusivity Samples - Limitations of
the Time-Lag Method

4.1.7 Example V: Diffusion in Synthetic Polymers 106

4.2 Diffusion Coefficients from Sorption/Desorption Kinetics 108

4.2.1 Batch Experiments 108

4.2.2 Column Desorption Experiments (Infinite Bath) 118

$\begin{array}{ll}\text { 4.3 Prediction of Diffusion Coefficients } & 125\end{array}$ 
5. DISSOLUTION KINETICS OF NON AQUEOUS PHASE LIQUIDS

5.1 Aqueous Solubility of Organic Compounds $\quad 130$

5.1.1 Solubility from Mixtures of Organic Compounds: Raoult's Law 130

5.1.2 Enhanced Solubility: Cosolvents, DOM, Surfactants and Colloids 134

5.2 Dissolution Kinetics

5.2.1 The Film Diffusion Model

136

5.2.2 Dissolution from Complex Mixtures: Two-Film Diffusion

138

5.2.3 Dissolution from NAPL Pools

6. RISK ASSESSMENT - REMEDIATION

6.1 Risk Assessment: Release Rates

6.1.1 Length of Mass Transfer Zones:

Maximum Flux and Maximum Concentration

Dissolution

150

Desorption

152

6.1.2 Diffusion from NAPL-Pools and Contaminant Flux Across the Capillary Fringe

157

6.2 Time Scales of Soil and Groundwater Remediation

161

6.2.1 Dissolution of Residual NAPL

161

6.2.2 Time for Dissolution of Pools

162

6.2.3 Desorption Time Scales

6.3 Transport by Diffusion Compared to Advection

REFERENCES

I. Analytical Methods: TCE and Phenanthrene

II. Methods of Solids Characterization

III. TCE-Diffusion Data: Time-Lag Method

IV. Tracer Diffusion Data

V. Examples for Long-Term Sorption Kinetics of Phenanthrene 


\section{FOREWORD}

The book is intended for geologists, hydrogeologists, and environmental engineers, who need to quantify transport phenomena in the field involving the molecular diffusion of organic contaminants in natural porous media such as soils, sediments, rocks, waste liner materials, etc. Since sorption/desorption kinetics as well as dissolution rates of organic contaminants are limited by slow molecular diffusion, emphasis is placed on the discussion of these processes. The book compiles methods for calculation of diffusion coefficients of organic compounds in aqueous solutions and vapor phase, as well as in natural porous media. Modeling of diffusive transport for various initial and boundary conditions is treated extensively based on analytical solutions of Fick's 2nd law and some simple numerical models (which may be solved using spreadsheets). Data are supplied on sorption/desorption rates of organic compounds in various soils and aquifer materials as well as on the dissolution kinetics of nonaqueous phase liquids (trapped residual phase and pools) in aquifers. Finally, the widespread difficulties in soil and groundwater decontamination which are due to slow diffusion processes are discussed, together with implications for groundwater risk assessment. 


\section{ACKNOWLEDGEMENTS}

This book is based on results of several research projects funded by PWAB (Projekt-Wasser-Abfall-Boden: PW89.081, PW92.113 PD 94.159, BadenWürttemberg, Germany) and the DFG (German Research Foundation: Gr971/51/2; Gr971/6-1/2). I thank my former advisors and coworkers at Stanford University, Department of Civil Engineering and Science where I started the study of the slow diffusion limited sorption/desorption processes (a long time ago), especially Martin Reinhard, Paul Roberts, Bill Ball, Jim Farrell, Matthias Kohler, Gary Curtis, and many others. I also appreciate the support of my colleagues at the "Lehrstuhl für Angewandte Geologie", University of Tübingen, especially Georg Teutsch, Rudi Liedl, Martin Sauter, Mike Herbert, and Thomas Ptak. I am grateful to all who supported me directly in the collection of the data, particularly Sybille Kleineidam and Hermann Rügner, Diana Loyek, Willi Pyka, Christoph Schüth, Christina Eberhardt, Thomas Gewald and Peter Merkel. I would also like to thank Bernice Nisch, Renate Riehle, Renate Seelig, Anne Hartmann-Renz, and Dagmar Kost for their technical assistance in the hydrogeochemistry laboratory. Many other students in Tübingen contributed to the database we have today: Tom Schiedek, Rainer Klein, Hansjörg Weiß, Jörg Danzer, Csaba Reisinger, Markus Boger, Tom Anders, Sylvia Vilsmaier, Daniela Zamfirescu, Adi Mattes, Norbert Seitz, Tom Boving, Stefan Mauch, Heiner Terton, Markus Ruess, and others. For their help in finishing this manuscript I would like to thank Csaba Reisinger (layout), Janet Witthaker (English of new Chapters) and Ingo Schlenker (final check of references and notation). 


\section{Notation}

The abbreviations shown in brackets represent the dimensionality of the variable being used: $M=$ mass; $L=$ length; $L^{3}=$ volume, $t=$ time .

$a=$ grain or particle radius [L]

$A_{o}=$ specific surface area, e.g. interfacial area per $\mathrm{m}^{3}$ porous medium $\left[\mathrm{L}^{2} \mathrm{~L}^{-3}\right]$

$A / V=$ surface to volume ratio of a particle [-]

$b, c, d=$ edges of slabs, parallelepipeds, cubes [L]

$C=$ solute concentration in aqueous or vapor phase $\left[\mathrm{M} \mathrm{L}^{-3}\right]$

$C_{e q}=$ equilibrium solute concentration in aqueous or vapor phase $\left[\mathrm{M} \mathrm{L}^{-3}\right]$

$C_{g}=$ solute concentration in vapor phase $\left[\mathrm{M} \mathrm{L}^{-3}\right]$

$C_{o c}=$ equilibrium solute concentration normalized to organic carbon $\left[\mathrm{M} \mathrm{L}^{-3}\right]$

$C_{o m}=$ equilibrium solute concentration normalized to organic matter $\left[\mathrm{M} \mathrm{L}^{-3}\right]$

$S=$ saturation concentration of solute in aqueous or vapor phase $\left[\mathrm{M} \mathrm{L}^{-3}\right]$

$C_{w}=$ solute concentration in water $\left[\mathrm{M} \mathrm{L}^{-3}\right]$

$C_{i, w}=$ aqueous concentration of component $i$ from a complex mixture $\left[\mathrm{M} \mathrm{L}^{-3}\right]$

$d=$ thickness of a layer or slab [L]

$d_{s}=$ solid density $\left[\mathrm{M} \mathrm{L}^{-3}\right]$

$D=$ diffusion coefficient $\left[\mathrm{L}^{2} \mathrm{t}^{-1}\right] ; D^{\prime}=$ normalized diffusion coefficient $[-]$

$D_{a}=$ apparent diffusion coefficient $\left[\mathrm{L}^{2} \mathrm{t}^{-1}\right]$

$D_{a} / a^{2}=$ diffusion rate constant $\left[\mathrm{t}^{-1}\right]$

$D_{\text {air }}=$ diffusion coefficient in air $\left[\mathrm{L}^{2} \mathrm{t}^{-1}\right]$

$D_{a q}=$ diffusion coefficient in aqueous phase $\left[\mathrm{L}^{2} \mathrm{t}^{-1}\right]$

$D_{g}=$ diffusion coefficient in gas phase $\left[\mathrm{L}^{2} \mathrm{t}^{-1}\right]$

$D_{e}=$ effective diffusion coefficient $\left[\mathrm{L}^{2} \mathrm{t}^{-1}\right]$

$D_{e g}=$ effective (gas) diffusion coefficient $\left[\mathrm{L}^{2} \mathrm{t}^{-1}\right]$

$D_{p}=$ pore diffusion coefficient $\left[\mathrm{L}^{2} \mathrm{t}^{-1}\right]$

$D_{\text {poly }}=$ polymer diffusion coefficient $\left[\mathrm{L}^{2} \mathrm{t}^{-1}\right]$

$D_{s, e}=$ effective surface diffusion coefficient $\left[\mathrm{L}^{2} \mathrm{t}^{-1}\right]$

$f=$ fractional uptake at equilibrium [-]

$f_{o c}=$ fraction of organic carbon $[-]$

$F=$ diffusive flux $\left[\mathrm{M} \mathrm{L}^{-2} \mathrm{t}^{-1}\right]$

$F^{\prime}=$ normalized diffusive flux $[-]$

$F_{f}=$ formation factor [-]

$F_{\text {stat }}=$ steady state diffusive flux $\left[\mathrm{M} \mathrm{L}^{-2} \mathrm{t}^{-1}\right]$

$h=$ thickness of an aquifer [L]

$H=$ Henry's law constant [-]

$i=$ hydraulic gradient [-]

$k_{f}=$ hydraulic conductivity $\left[\mathrm{L} \mathrm{t}^{-1}\right]$

$K=$ BET sorption coefficient $\left[\mathrm{L}^{3} \mathrm{M}^{-1}\right]$

$K_{d}=$ distribution coefficient, sorption coefficient $\left[\mathrm{L}^{3} \mathrm{M}^{-1}\right]$

$K_{d, a}=$ nonequilibrium, apparent sorption coefficient $\left[\mathrm{L}^{3} \mathrm{M}^{-1}\right]$

$K_{F r}=$ Freundlich sorption coefficient $\left[\mathrm{L}^{3} \mathrm{M}^{-1}\right]$

$K_{L}, K_{T}=$ Langmuir, Toth sorption coefficient $\left[\mathrm{L}^{3} \mathrm{M}^{-1}\right]$ 
$K_{o c}=$ organic carbon based distribution coefficient, sorption coefficient $\left[\mathrm{L}^{3} \mathrm{M}^{-1}\right]$

$K_{o m}=$ organic matter partition coefficient $\left[\mathrm{L}^{3} \mathrm{M}^{-1}\right]$

$K_{\text {ow }}=$ octanol/water partition coefficient [-]

$L_{c}=$ length of contaminated zone [L]

$l=($ shortest $)$ distance in porous media [L]

$l_{e}=$ effective path length in porous media $[\mathrm{L}]$

$m=$ Archie's law exponent [-]

$m_{d}=$ solid mass [M]

$m_{\text {air }}, m_{g}, m_{\text {sol }}, m_{s}=$ molecular weight of air, gas, solvent and solute, resp. [g mol $\left.{ }^{-1}\right]$

$M=$ mass of solute which has diffused into / out of a particle or porous medium [M]

$M_{e q}=$ mass of solute in a particle under equilibrium conditions [M]

$M_{s}=$ mass of solute in a particle at a given time [M]

$M_{t e}=$ mass of solute in a particle after a certain exposition time $t_{e}[\mathrm{M}]$

$n=$ intergranular porosity $[-]$

$n_{e}=$ (flow) effective porosity [-]

$n_{g}=$ air filled porosity [-]

$q=$ sorbed concentration, sorbate concentration in a solid $\left[\mathrm{M} \mathrm{M}^{-1}\right]$

$q_{\max }=$ maximum sorbate concentration in a solid $\left[\mathrm{M} \mathrm{M}^{-1}\right]$

$r=$ radial distance [L]

$r_{h}=$ hydraulic radius [L]

$o c=$ organic carbon content $\left[\mathrm{mg} \mathrm{kg}^{-1}\right]$

$P=$ pressure $[\mathrm{atm}]$

$P_{x}=$ probability

$R e=$ Reynolds number [-]

$R_{d}=$ Retardation factor [-]

$R_{p}=$ pore retardation factor $[-]$

$S=$ water solubility $\left[\mathrm{M} \mathrm{L}^{-3}\right]$

$S c, S h=$ Schmidt number and Sherwood number [-]

$S^{\circ}=$ saturation degree, water and NAPL $[-]$

$\mathrm{T}=$ temperature $\left[\mathrm{K},{ }^{\circ} \mathrm{C}\right]$

$t=$ time $[\mathrm{t}]$

$t_{c}=$ mean residence time; contact time[t]

$t_{e}=$ exposure (equilibration) time [t]

$t_{\text {lag }}=$ lag-time $[\mathrm{t}]$, time to reach about $1 / 3$ of steady state conditions

$t_{96} ; t_{99}=$ time to desorbe $90 \% 99 \%$ of a contaminant [t]

$v_{a}=$ groundwater flow velocity $\left[\mathrm{L} \mathrm{t}^{-1}\right]$

$V_{\text {air }}, V_{g}=$ molar volume of air and gas $\left[\mathrm{L} \mathrm{mol}^{-1}\right]$

$V_{o m}=$ molar volume of organic matter $\left[\mathrm{L} \mathrm{mol}^{-1}\right]$

$V_{w}=$ volume of water, i.e. in a batch system $\left[\mathrm{L}^{3}\right]$

$V^{\prime \prime}=$ LeBas molar volume $\left[\mathrm{cm}^{2} \mathrm{~mol}^{-1}\right]$

$w, w_{a d}=$ water content based on dry weight of solids, weight fraction of water adsorbed onto solids (e.g. at a relative humidity of $98.8 \%[-]$

$x=$ distance $[\mathrm{L}]$

$X_{i}=$ fraction of solute in component $i$ under equilibrium conditions; and fraction of instantaneous sorption $[-]$ 
$X_{S}=$ length of mass transfer zone; saturation distance [L]

$Z_{o}=$ thickness of contaminated zone $[\mathrm{L}]$

$Z_{S}=$ equivalent saturation height in pool dissolution [L]

$\bar{z}=$ mean square displacement (vertical)

$1 / n=$ Freundlich exponent $[-]$

\section{Greek symbols}

$\alpha=$ capacity factor $\left(\varepsilon+K_{d} \rho\right)[-]$

$\alpha_{t}=$ transverse, vertical dispersivity $\left[\mathrm{L}^{2} \mathrm{~s}^{-1}\right]$

$\beta=$ ratio of solute mass dissolved to mass in the solid phase in a batch system [-]

$\delta=$ constrictivity factor $(<1)[-]$

$\varepsilon=$ porosity of porous media, intraparticle porosity [-]

$\varepsilon_{t}=$ transport-through porosity $[-]$

$\gamma=$ proportionality factor (first order and diffusion kinetics) [-]

$\gamma_{i, w}, \gamma_{i, o}=$ activity coefficient in water or organic mixture [-]

$\gamma_{o m}=$ activity coefficient in organic matter [-]

$\eta=$ dynamic viscosity $\left[\mathrm{N} \mathrm{s} \mathrm{m}^{-2} ; \mathrm{Pa} \mathrm{s} ; \mathrm{J} \mathrm{s} \mathrm{m}^{-3}\right]$

$\lambda=$ first order rate coefficient $\left[\mathrm{L} \mathrm{t}^{-1}\right]$

$\lambda_{p}=$ ratio of molecular solute diameter to pore diameter [-]

$\theta=$ liquid to solid ratio in a batch sorption system; NAPL filled porosity [-]

$\rho=$ bulk density of porous media $\left[\mathrm{M} \mathrm{L}^{-3}\right]$

$\rho_{o}, \rho_{o m}=$ density of an organic liquid and organic matter $\left[\mathrm{M} \mathrm{L}^{-3}\right]$

$\sigma=$ standard deviation [-], cosolvent power

$\sigma_{a q}, \sigma_{\text {rock }}=$ electrical conductivity of pore water and rock

$\tau_{f}=$ tortuosity factor $[-]$ 